\title{
Modeling Sediment Yields in A Small Gully of the Sichuan Hilly Basin Using Geowepp Model
}

\author{
Zheng Jinjun \\ School of Resources and Environment \\ University of Electronic Science and Technology of China \\ Chengdu, China, 611731, 13980556225 \\ jinjunzh@uestce.edu.cn
}

\author{
Hong Chao \\ School of Resources and Environment \\ University of Electronic Science and Technology of China \\ Chengdu, China, 611731
}

\begin{abstract}
The spatial pattern of soil erosion and deposition on catchment scale are predicted by the GeoWEPP model in a small catchment of the Sichuan Hilly Basin. The estimated sediment delivery per unit area and sediment delivery ratio are 2760 t•km2•yr-1 and 0.485, respectively. Compared with the results derived by the second soil erosion survey based on remote sensing, the results by the GeoWEPP model are reasonable. According to the spatial pattern of sediments simulated by the GeoWEPP, the slight soil erosion rates for the wood land and patter show that the woodland have good soil and water conservation benefit than cultivated slopes. In the same time, the GeoWEPP are useful tool to establish effective policy for comprehensive treatment of small catchment in view of the soil erosion and deposition could be estimated on time-scale and spatial-scale by the GeoWEPP.
\end{abstract}

Keywords-component; The GeoWEPP model; model simulation; soil redistribution; the Sichuan Hilly Basin

\section{INTRODUCTION}

Estimating sediment yield and exploring the spatial pattern of soil redistribution is key to the land use management and river management. Decision-makers operating at different scales of interest and responsibility have to assess the distribution, extent, and severity of soil erosion and sedimentation. To seek solutions in handling natural and human actions related to this type of nonpoint source pollution, the linkage of distributed assessment models and Geographical Information Systems (GIS) at various spatial and temporal scales is in high demand. With the development of the computer sciences, many Hydrological Model such as AGNPS, GeoWEPP and LISEM are used in estimating the sediment yield in the spatial scale. Among those Models of hydrological processes, the GeoWEPP model is the only model, which can exploring the spatial pattern of soil erosion and soil disposition. The GeoWEPP model utilizes readily available digital georeferenced information from publicly accessible Internet sources such as the U.S. Geological Survey digital elevation models, topographical maps, and land use data as well as Natural Resources Conservation Service soils maps. Together with parameter sets of the WEPP database containing statistical parameter sets from more than 2600 U.S. climate stations, GeoWEPP enables even non-GIS-and-modeling users to derive and prepare valid model input parameters to assess representative conditions in an area of interest [1][2].

The study is sponsored by The Chinese Academy of Sciences Western Action Plan (No. KZCX2-XB3-09) and the Basic Scientific Research of Central College. (No. 103.1.2 E022050205).
The Sichuan Hilly Basin is one of the most densely populated agricultural regions in China and the area represents one of the most severely eroded regions in the Upper Yangtze River Basin due to natural and man-made cause [3][4].The objectives of this paper were to estimate the sediment yield and runoff in Linshan Gully using the GeoWEPP model, to validate the applicability of GeoWEPP for estimating sediment yields in southwestern China, and to evaluate the benefit of the soil and water conservation methods.

\section{MATERIALS AND METHODS}

\section{A. The Study Area}

A small gully, Linshan Gully, was selected as the focus of the investigation. Linshan Gully, the small catchment near the Linshan Village, Yanting County, Sichuan Province has a drainage area of $31.79 \mathrm{hm} 2$ and its elevation ranges between 400 and $535 \mathrm{~m}$. The mean annual precipitation for the study area is estimated to be about $826 \mathrm{~mm}$, with most precipitation occurring between June and September. The soils in the study area, derived from purple mudstone and sandstone, are generally shallow and are classified as Regosols in FAO soil Unit [5][6].

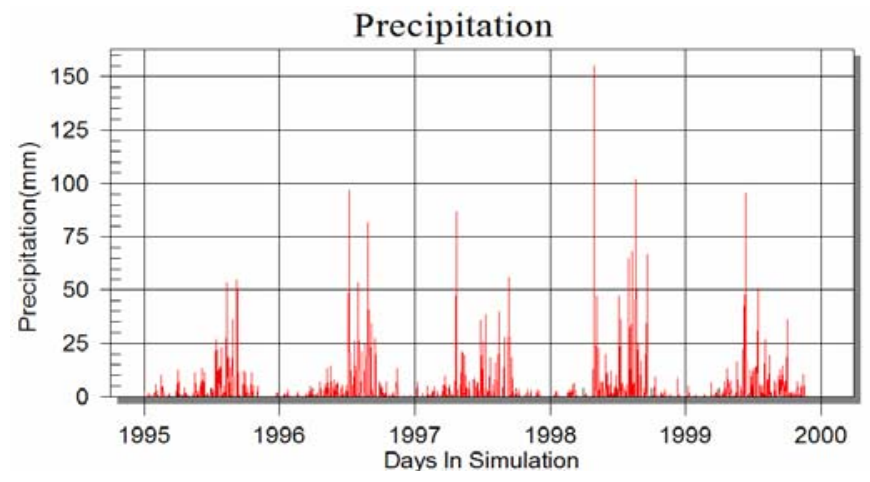

Figure 1. the distribution of precipitation of the study area

\section{B. Methods}

GIS in model linkages are dominantly used for data preprocessing and visualization of available data sources as well as the handling of data to apply environmental assessment models. A GIS-driven graphical user interface is a user-friendly approach to combine the decision-support of an environmental 
prediction model and the spatial capabilities of a GIS for practical assessment purposes. A useful and successful implementation of an environmental model assessment approach requires the use of widely available data sets and the preparation of model input parameters to allow reliable model predictions. The input data for the GeoWEPP model includes the Digital Elevation Models (DEM), Land use map, Soils map and Climate data. In a nutshell, all map data needs to be projected into UTMs and converted into ASCII files.

\section{1) Preparing the DEM}

The DEM is used to delineate the channel network, determine the sub-catchments in your watershed, and generate the hillslope information such as slope, length, etc. for WEPP. The DEM is necessary for the GeoWEPP simulation. The imported DEMs is a hill shade map that allows even DEMinexperienced people to get an idea about the topography of the selected area. The process of the DEM include import of digital elevation models, orientation to locate area of interest, channel and watershed delineation and other model input parameters.

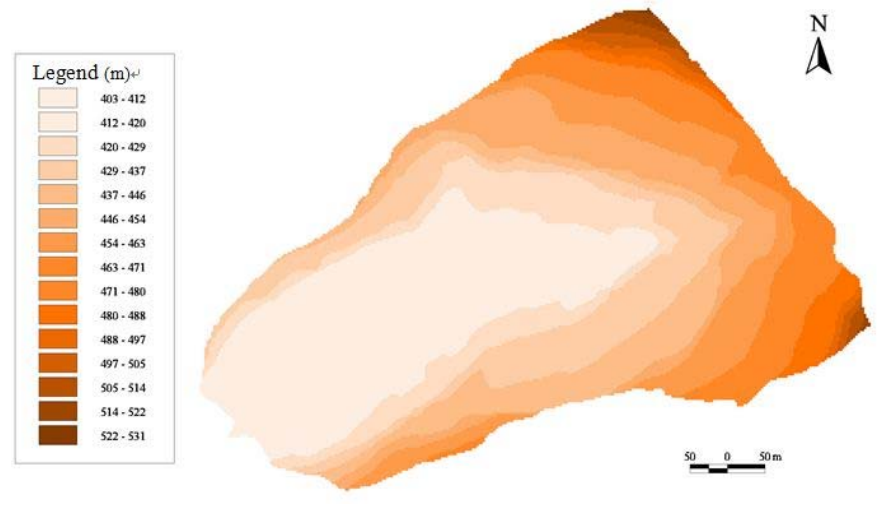

Figure 2. DEM of the small watershed

\section{2) Preparing the Landuse map}

The land cover is indicated in management file based on growth and mortality parameters. In this study, the necessary management file data were obtained by field measurements and then inputed into the WEPP. Then, the management file was generated for different land use types (i.e. water, building, wood land, grass land, patty and sloping field) for each subwatershed for simulation. In the course of processing, WEPP generates interrill cover data for each year using growth parameters, soil data, andclimate data. In the GeoWEPP simulation, the land cover layer (landcov.asc) is generated based on management file in ArcView environment. Then, land cover text file (landcov.txt) is developed according to associated land use types. The land cover text file is used by GeoWEPP and WEPP/TOPAZ Translator to determine the description that corresponds with the landcover layer in GeoWEPP.

In this section, a landuse TIFF image will be converting into an ASCII rasterfile just like the DEMs. The landuse is stored as a TIFF image, but it is not a GeoTIFF; this piece of data has its spatial reference saved in a separate TIFF WorldFile $(* t f w)$. Without the file, the TIFF image will not be projected properly when loaded into ArcMap.

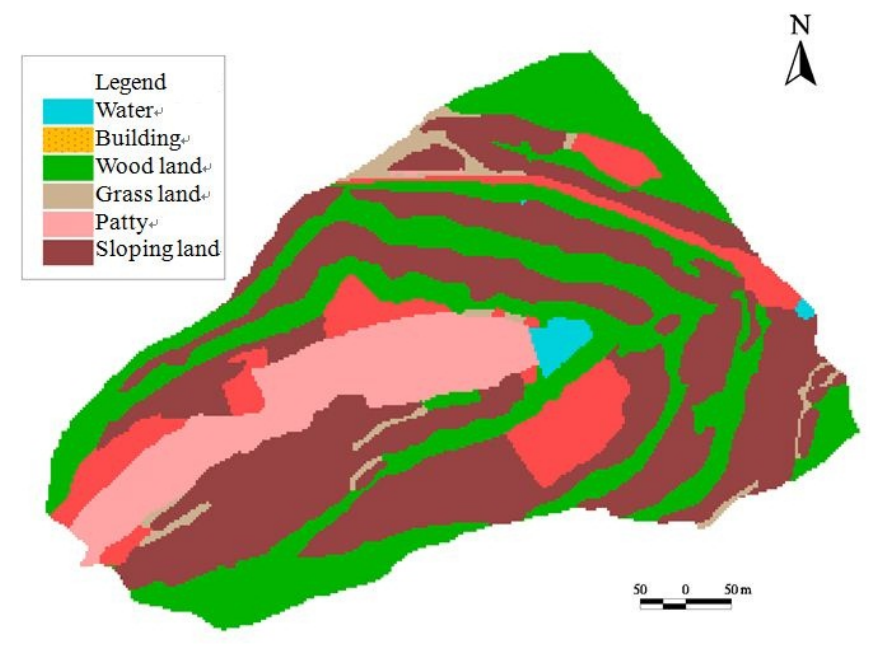

Figure 3. the management map of the small watershed

\section{3) Preparing the soil map}

Accurate describing of soil property values in WEPP is necessary for predicting sediment yield and runoff. In WEPP, critical parameters in the soil file are soil texture, albedo, saturation level,hydraulic conductivity, rill erodibility and interrill erodibility, and critical shear. These parameters areobtained from data collection or calculated by the WEPP model. In the present study, soil parameters were obtained from soil samples collected from the study area.

For running the GeoWEPP model, the soil map layer (soilsmap.asc) is generated from the soil input file in ArcView environment. Then, soil text file (soilsmap.txt) is established according to the associated land cover types such as water, building, wood land, grass land, patty and sloping field. The soil text file is used by GeoWEPP and WEPP/TOPAZ Translator to determine the description that corresponds with the soil map layer in GeoWEPP. In the text file, special codes are assigned to represent the raster cell values in the soil map layer. The values are to be followed by the description to describe soil types. In order to run GeoWEPP and WEPP/TOPAZ, soil text file is used as a bridge between WEPP/TOPAZ Translator and soil map layer.

The GeoWEPP model requires four input files including slope, climate, soil, and management files to describe hillslope geometry, meteorological characteristics, soil properties, and ground cover, respectively. In this study, sub-watersheds and channels in the study area were derived from $1 \mathrm{~m}$ DEMs generated by using TOPAZ. The climate files were established by the climate data of Yanting County range from 1956 to 1999. The soil parameters were measured at representative fields and the necessary management file data (i.e. the amount of vegetation, duff, litter, and woody debris) were obtained by field measurements.

\section{RESULT AND DISCUSSION}

In the GeoWEPP, the slope and sub-watershed are divided using the Digital Elevation Model, and then the sediment yield are simulated according to the landuse type, soil map, and climate data. As shown in figure 4., 38 slope are divided from 
the watershed. In the simulating period from 1995 to 1999, there are 37 large rainfall events. In the37 large rainfall events, total volume of rainfall, runoff and sediment are $1836.3 \mathrm{~mm}$, $200307 \mathrm{~m} 3$ and $2058436 \mathrm{t}$. Detailed simulation results are shown in Table 1.

TABLE I. THE RESULT DERIVED BY GEOWEPP

\begin{tabular}{|c|c|c|c|c|}
\hline \multirow{2}{*}{ Year } & Large storm & Precipitation & Runoff & Sediment \\
\hline & times & $\mathrm{mm}$ & $\mathrm{m}^{3}$ & $\mathrm{t}$ \\
\hline 95 & 3 & 154.4 & 9076.15 & 90775.4 \\
\hline 96 & 7 & 371.5 & 33228.06 & 318654.2 \\
\hline 97 & 7 & 277.6 & 26686.25 & 262079.7 \\
\hline 98 & 14 & 760.1 & 103468.1 & 1062693 \\
\hline 99 & 6 & 272.7 & 27848.44 & 324233.9 \\
\hline Total & 37 & 1836.3 & 200307 & 2058436 \\
\hline Legend \\
\hline
\end{tabular}

Figure 4. The off-site map of the small watershed

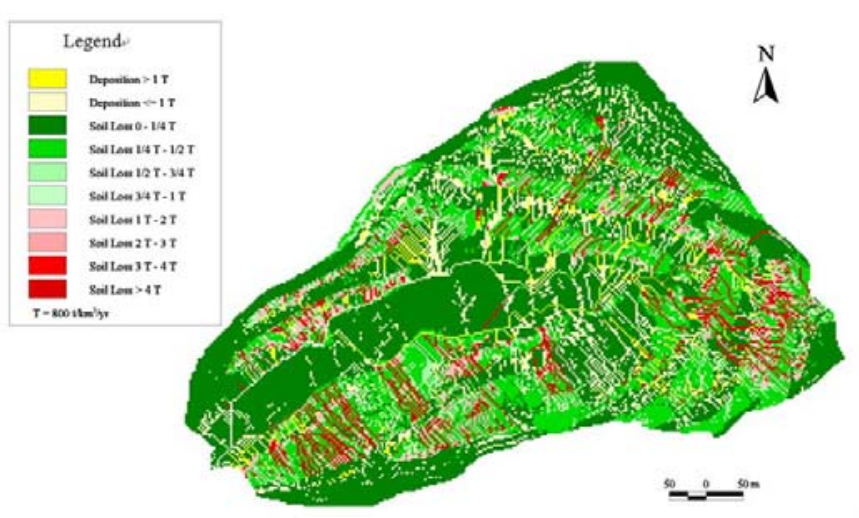

Figure 5. The off-site map of the small watershed

The sediment yield rates from 1995 to 1999 simulated by the GeoWEPP model is $1280 \mathrm{t} \bullet \mathrm{km}-2 \bullet \mathrm{yr}-1$ and the Sediment delivery ratio is 0.565 . The average sediment yield from the outlet of the catchment is $412.6 \mathrm{t} \cdot \mathrm{yr}-1$. According to the result derived by the radionuclide tracing, the sediment transport modulus is $642 \mathrm{t} \bullet \mathrm{km}-2 \bullet \mathrm{yr}-1$ for the Wujiagou catchment, nearby the study catchment[4]. The similar results derived by radionuclide method and the result derived by the GeoWEPP shows that the simulation using the GeoWEPP is credible. The figure 4. and figure 5. are the on-site map and off-site map of the small watershed, respectively. The allowing erosion rates is $800 \mathrm{t} \cdot \mathrm{km}^{-2} \cdot \mathrm{yr}^{-1}$ for the on-site map and the off-site map. As shown in figure 5., the spatial pattern of soil redistribution can be well presented. The soil deposition shows a messy condition, and main locates in the base of slope, low-lying parts of the catchment and lower sites of the patty. Alternatives to the soil deposition, the soil erosion is related to the landuse and slope gradient. For the whole catchment, the moderate erosion is the main erosion types. The soil erosion rates for the patty, wood land and grass land are very gentle, and those for the slope cultivated land are mainly moderate. Some steep slope cultivated land have deep erosion. From the figure 4 . and figure 5., the soil erosion rates for the slope cultivated land, grass land, wood land and patty show a declining trend. The gentle erosion rates for the wood land and patty shows that the forest have good soil and water conservation benefit.

The results from the monthly predictions showed higher accuracy in sediment yields and a slight lower accuracy in runoff predictions even though the values are within the acceptable range at a 90 percent confidence level. According to the spatial pattern of sediments simulated by the GeoWEPP, the slight soil erosion rates for the wood land and patter show that the woodland has good soil and water conservation benefit than cultivated slopes.

\section{CONCLUSION}

According to the spatial pattern of sediments simulated by the GeoWEPP, the slight soil erosion rates for the wood land and patter show that the woodland have good soil and water conservation benefit than cultivated slopes. And the soil erosion and deposition on time-scale and spatial-scale by the GeoWEPP is reasonable. The overall results indicated that the GeoWEPP model can assist watershed-related management institutions to quickly and accurately generate acceptable predictions of sediment yield and runoff outputs in textual or graphical format based on digital data base of the watershed.

\section{REFERENCES}

[1] Govers, G., Quine, T. A., Desmet, P. J. J. and Walling, D. E. "The relative contribution of soil tillage and overland flow erosion to soil redistribution on agricultural land.," Earth Surf. Pro. Landforms, 21: 929-946, 1996.

[2] Lobb, D. A., Kachanoski, R. G. and Miller, M. H. "Tillage translocation and tillage erosion on shoulder slope landscape positions measured using 137Cs as a tracer, ” Canadian Journal of Soil Science. 75: 211--218. 1995.

[3] Soil Research Group of Institute of Mountain Hazards and Environment, CAS (SRG-IMHE). Purple Soils in China (Volume 1) (in Chinese), Science Press, Beijing, 349pp, 1991.

[4] Zhu, B., Chen, S., You, X., Peng, G. and Zhang, X. W. "Soil fertility restoration on degraded upland of purple soil," Acta Pedologica Sinica (in Chinese), 39(5): 743—749, 2002.

[5] Revel, J. C. and Guiresse, M. "Erosion due to cultivation of calcarcous clay soils on the hillsides of south west France. I. Effect of former farming practices,” Soil \& Tillage Research, 35(3): 147--155. 1995.

[6] Ritchie, J. C. and McHenry, J. R. “Application of radioactive fallout caesium-137 for measuring soil erosion and sediment accumulation rates and patterns: A Review, ” Journal of Environmental Quality, 19: 215-233. 1990. 